\title{
Development of Marathon Brand Element Scale
}

\author{
Mengmeng Huang ${ }^{1}$ Chuan-ming $\mathrm{Cai}^{2, *}$ Yao-Chuan Chang ${ }^{3}$
}

\author{
${ }^{1}$ School of Physical Education, Jimei University, Xiamen, China \\ ${ }^{2}$ School of Physical Education, Jimei University, Xiamen, China \\ ${ }^{3}$ Zhaoqing University, zhaoqing, China \\ *Chuan-ming Cai. Email: 1362171804@qq.com
}

\begin{abstract}
The purpose of this paper is to develop a scale of marathon event brand elements, which provides a quantitative tool for event brand building. And the methods are literature review, questionnaire survey and mathematical statistics. It is concluded that the scale consists of 42 items in five dimensions: marathon brand symbol, culture, service, marketing and influence. The results of confirmatory factor analysis show that the fitness between the assumed structure model and sample data is acceptable. The results of reliability and validity show that the scale has good reliability and validity, which can be used as a tool for brand building of marathon events, and can provide the organizing committee with the attitude of contestants and the specific path to start a marathon brand building. ( $\mathrm{x} 2 / \mathrm{df}=3.668, \mathrm{RMSEA}=0.082, \mathrm{IFI}=0.791$, $\mathrm{CFI}=0.790, \mathrm{PGFI}=0.648, \mathrm{PNFI}=0.694$; Cronbach $\alpha=0.954$ in the total questionnaire, and Cronbach $\alpha$ ranges from 0.839 to 0.944 in five dimensions).
\end{abstract}

Keywords: Marathon brand elements, Scale, Exploratory factor analysis, Confirmatory factor analysis.

\section{INTRODUCTION}

With the development of marathon events at home and abroad, the construction of marathon brand has been put on the agenda. However, most of the researches on marathon brand directly use brand related theories to describe a specific event qualitatively from brand positioning, brand identification, brand marketing, brand promotion or other aspects ${ }^{[1-8]}$. Practice has shown that was of little help to the marathon. The above research model avoids a common question, that is, what is the marathon brand and what are the specific elements? marathon event is different from the general material product brand, and the theory of directly applying the brand field shows its inapplicability. The brand element is the foundation of brand building. It is of great significance to study the brand elements of marathon for its brand building ${ }^{[9]}$. Therefore, this research attempts to explore the brand elements of marathon events and develop a marathon event brand element scale to provide a theoretical basis for marathon event brand building.

\section{LITERATURE REVIEW}

It can be seen from the relevant research that scholars have different views on the research of brand elements, but most of them think that the brand is composed of some hard elements, such as brand name, slogan, slogan, theme and some soft elements, such as product quality, cultural concept, publicity and marketing. Regarding the brand elements of sports events, although there are not many literatures, it can be summarized that they generally include such elements as event brand symbols, event influence, event products, and event culture. Event brands are different from general product brands and should form a unique theory of event brands ${ }^{[10-23]}$. Event brand elements include event brand symbols, event brand culture and event products, and must be marketed. Marathon belongs to sports events, but also has its particularity. This paper compiles a marathon brand element scale from five dimensions of marathon brand symbol, culture, service, influence and marketing based on the above theory and the uniqueness of a marathon.

\section{RESEARCH METHODS}

An initial scale of 50 measurement items was drawn up from 5 dimensions and Likert's 5-level scoring method was used. The research took the participants of the Xiamen (Haicang) International Half Marathon as the survey subjects and was distributed on the scene of the event on December 8, 2019. A total of 865 questionnaires were retrieved and 798 valid questionnaires were collected with an effective rate of about $92 \%$. The study 
used IBM SPSS Statistics 25.0 and Amos 24.0 to analyze the questionnaire data, and tested the validity of the questionnaire through exploratory factor analysis and confirmatory factor analysis. The recovered 798 valid questionnaires were randomly divided into 2 equal parts, one (399 sheets) was used for exploratory factor analysis, and the other (399 sheets) was used for confirmatory factor analysis.

\section{RESULTS}

\subsection{Project analysis}

The project analysis adopts the extreme group test method, which aims to test the suitability or feasibility of the compiled scale or individual items of the test. And the data result of the item analysis shows the value of Sig. of all the items on the scale, that is, $t<0.01$, indicating that the scale items in this study are distinguishable and all are retained.

\subsection{Exploratory factor analysis}

\subsubsection{KMO and Bartlett sphere inspection}

The study first conducted KMO and Bartlett sphere tests. The KMO value is equal to 0.936 , which indicates that the factor analysis of the sample data is very appropriate; the significance probability value of the Bartlett sphere test is $\mathrm{p}<0.01$, reaching a significant level, which means that there were common factors among the 50 items in the marathon brand element scale, and the data was suitable for factor analysis.

\subsubsection{Item selection and common factor extraction}

The study adopts the method of limited extraction factors. After extracting 5 common factors, the cumulative explained variance is $54.694 \%$, and the result of factor analysis is acceptable. In the rotated factor load matrix of the first exploration, there are 9 items lower than 0.5 , which are event record, high-tech application, convenient registration, regional human history, competition package design, city competition positioning, exquisite medals, medical security and post competition recovery. Finally, 8 items were eliminated and 42 items were retained. In exploratory factor analysis, if the user deletes a certain item, an explanation of the factor structure is found even more difficult, the original deleted item variables can be re-incorporated ${ }^{[24]}$. After removing the "individual completion video" in this study, it is found that the factor structure is chaotic. Therefore, the "individual completion video" is retained.

\subsubsection{Factor naming}

In the factor loading diagram after rotation, the items present a ladder-like distribution into 5 dimensions. As it is shown in Table 1. Factor 1, including 18 items, is mainly related to marathon marketing, so it is named as marathon brand marketing. Factor 2, is named as marathon brand symbol. Factor 3, is named as marathon brand service. In addition, "volunteer service" in factor 1 obviously belongs to the service of marathon, so it is included in factor 3. Factor 4, is named as marathon brand culture. Factor 5, is named as marathon brand influence.

Table 1. Rotated component matrix

Rotated component matrix $\mathrm{A}^{\mathrm{a}}$

\begin{tabular}{lllll}
\hline & \multicolumn{3}{c}{ component } \\
\cline { 2 - 4 } & 1 & 2 & 3 & 4 \\
supporting activities & .747 & .747 & \\
press conference & .716 & \\
marathon Forum & .708 & \\
sponsor visibility & .701 & \\
media publicity & .699 & \\
hotel accommodation & .693 & \\
star marketing & 685
\end{tabular}




\section{Rotated component matrix $A^{a}$}

\begin{tabular}{|c|c|c|c|c|c|}
\hline & \multicolumn{5}{|c|}{ component } \\
\hline & 1 & 2 & 3 & 4 & 5 \\
\hline travel recommendation & .682 & & & & \\
\hline marathon Expo & .678 & & & & \\
\hline bonus setting & .671 & & & & \\
\hline public welfare activities & .641 & & & & \\
\hline event information platform & .632 & & & & \\
\hline urban development concept & .632 & & & & \\
\hline exclusive photo service & .595 & & & & \\
\hline consultation and guidance & .593 & & & & \\
\hline construction of official website & .536 & & & & \\
\hline volunteer service & .511 & & & & \\
\hline individual completion video & .484 & & & & \\
\hline event logo & & .782 & & & \\
\hline event mascot & & .769 & & & \\
\hline event song & & .735 & & & \\
\hline event name & & .729 & & & \\
\hline main colors of event & & .711 & & & \\
\hline event slogan & & .558 & & & \\
\hline event theme & & .527 & & & \\
\hline mobile toilet configuration & & & .754 & & \\
\hline package access & & & .734 & & \\
\hline bus feeder service & & & .732 & & \\
\hline supplies & & & .723 & & \\
\hline sign guide & & & .617 & & \\
\hline clothing quality & & & .614 & & \\
\hline keepsake & & & .572 & & \\
\hline fair and just & & & & .762 & \\
\hline
\end{tabular}


Rotated component matrix $\mathrm{A}^{\mathrm{a}}$

\begin{tabular}{|c|c|c|c|c|c|}
\hline & \multicolumn{5}{|c|}{ component } \\
\hline & 1 & 2 & 3 & 4 & 5 \\
\hline venue atmosphere & & & & .704 & \\
\hline track environment & & & & .689 & \\
\hline crisis handling capability & & & & .636 & \\
\hline code of conduct for employees & & & & .608 & \\
\hline marathon spirit & & & & .593 & \\
\hline event level & & & & & .840 \\
\hline event scale & & & & & .791 \\
\hline event record & & & & & 612 \\
\hline \multicolumn{6}{|c|}{ Extraction method: principal component analysis. } \\
\hline Rotation method: Caesar norma & 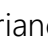 & & & & \\
\hline
\end{tabular}

\section{3. confirmatory factor analysis}

The initial model is first set as a secondary-order confirmatory model, and the secondary-order structure can explain all the first-order factor constructs ${ }^{[25]}$. The 42 items are divided into 5 dimensions. The other data $(\mathrm{n}=$ 399) used for validation group was imported into Amos
25.0 for calculation, and the model estimated various fitting indexes are shown in Table 2. In the output report indicators, we usually refer to the chi square degree of freedom ratio, RMR, RMSEA, IFI, CFI, PGFI and PNFI. The results show that the theoretical model of the marathon brand factor scale in this study has a good fit with the actual sample data, and it is more reasonable.

Table 2. List of confirmatory factor analysis of marathon brand constituent elements scale

\begin{tabular}{|c|c|c|c|c|c|c|c|c|c|}
\hline $\begin{array}{l}\text { Fitting } \\
\text { index: }\end{array}$ & $x 2$ & DF & $\mathrm{X} 2 / \mathrm{DF}$ & RMR & RMSEA & $|F|$ & $\mathrm{CFI}$ & PGFI & PNFI \\
\hline $\begin{array}{l}\text { Reference } \\
\text { standard }\end{array}$ & - & - & $<5$ & $<0.05$ & $<0.1$ & $>0.8$ & $>0.8$ & $>0.5$ & $>0.5$ \\
\hline $\begin{array}{l}\text { Fitting index } \\
\text { value }\end{array}$ & 2985.928 & 814 & 3.668 & 0.051 & 0.082 & 0.791 & 0.790 & 0.648 & 0.694 \\
\hline $\begin{array}{l}\text { Is it in line } \\
\text { with }\end{array}$ & & & yes & close & yes & close & close & yes & yes \\
\hline
\end{tabular}

\section{4. reliability and validity test}

In this study, Cronbach's alpha coefficient method is used to test the internal reliability of Marathon brand element scale. If the $\alpha$ coefficient is above 0.8 , it indicates that the scale has high reliability ${ }^{[26]}$. The reliability test values of the various levels of the scale and the total scale in this study are shown in Table 3. The Cronbach $\alpha$ of the total questionnaire is 0.954 , and the Cronbach $\alpha$ of the five 
dimensions ranges from 0.839 to 0.944 . So, the scale has good reliability.

Table 3. Reliability test value of scale Cronbach's alpha coefficient method

\begin{tabular}{lllc}
\hline Dimension & Cronbach & Based on Standardization & Number of items \\
& & Project & Cronbach $\alpha$ \\
& & 0.944 & 18 \\
\hline marathon brand marketing & 0.944 & 0.897 & 7 \\
marathon brand symbol & 0.897 & 0.863 & 8 \\
marathon brand service & 0.861 & 0.843 & 6 \\
marathon brand culture & 0.839 & 0.859 & 3 \\
marathon brand influence & 0.859 & 0.953 & 42 \\
\hline
\end{tabular}

This study combs the measurement items of the marathon brand building scale from five dimensions based on the theory, then through exploratory factor analysis, it proves that the construction validity of the scale is good. finally, another set of data is used for confirmatory factor analysis to further verify the appropriateness and authenticity of the construction validity of the scale. The results are in line with the standard, so the structure validity of marathon brand element scale is good.

\section{FORMAL SCALE OF BRAND ELEMENTS OF MARATHON EVENTS}

The formal scale of marathon brand elements was developed after a rigorous scale compilation procedure, which consists of 5 dimensions and 42 items, like table 4.

Table 4. Formal Scale of marathon brand constituent elements scale

\begin{tabular}{|c|c|c|c|}
\hline \multicolumn{4}{|c|}{ Formal scale of Marathon brand elements } \\
\hline class a & second level & Level 3 & Serial number \\
\hline \multirow{11}{*}{ Brand e } & \multirow{9}{*}{ Symbol } & event name & 1 \\
\hline & & event logo & 2 \\
\hline & & event theme & 3 \\
\hline & & event slogan & 4 \\
\hline & & event song & 5 \\
\hline & & & \\
\hline & & main colors of the event & 6 \\
\hline & & event mascot & 7 \\
\hline & & sign guide & 8 \\
\hline & \multirow[t]{2}{*}{ service } & bus feeder service & 9 \\
\hline & & volunteer service & 10 \\
\hline
\end{tabular}




\begin{tabular}{|c|c|c|c|}
\hline \multicolumn{4}{|c|}{ Formal scale of Marathon brand elements } \\
\hline class a & second level & Level 3 & Serial number \\
\hline & & supplies & 11 \\
\hline & & package access & 12 \\
\hline & & keepsake & 13 \\
\hline & & mobile toilet configuration & 14 \\
\hline & & clothing quality & 15 \\
\hline & & marathon spirit & 16 \\
\hline & & fair and just & 17 \\
\hline & & crisis handling ability & 18 \\
\hline & Culture & & \\
\hline & & code of conduct for employees & 19 \\
\hline & & venue atmosphere & 20 \\
\hline & & track environment & 21 \\
\hline & & marathon expo & 22 \\
\hline & & supporting activities & 23 \\
\hline & & marathon forum & 24 \\
\hline & & press conference & 25 \\
\hline & & fans & 26 \\
\hline & & media publicity & 27 \\
\hline & & sponsor visibility & 28 \\
\hline & & urban development concept & 29 \\
\hline & & public welfare activities & 30 \\
\hline & Marketing & & \\
\hline & & star marketing & 31 \\
\hline & & official website construction & 32 \\
\hline & & tourism recommendation & 33 \\
\hline & & event information platform & 34 \\
\hline & & consultation and guidance & 35 \\
\hline & & exclusive photo service & 36 \\
\hline & & hotel accommodation & 37 \\
\hline & & Individual completion video & 38 \\
\hline & & bonus setting & 39 \\
\hline
\end{tabular}


Formal scale of Marathon brand elements

\begin{tabular}{|c|c|c|c|}
\hline class a & second level & Level 3 & Serial number \\
\hline & & event level & 40 \\
\hline & influence & event scale & 41 \\
\hline & & event record & 42 \\
\hline
\end{tabular}

\section{DISCUSSION}

The research is a preliminary exploration for the development of the marathon brand element scale. As a unique type of brand, marathon brand not only has the common characteristics of general material product brand elements, but also has the particularity of its events. Previous studies on marathon event brands have mostly directly adopted theories in the brand field, ignoring the particularity of their events. However, the difference between this paper and previous studies is that it is distinguished marathon event brands from general material product brands, and based on the particularity of the event, a scale of the elements of the marathon event brand has been developed, which enriches the marathon event brand theory and solves the problem of which elements constitute the marathon event brand.

Marathon organizers can build their brand based on the content of the scale when organizing the event. For example, the symbol dimension includes 7 items, event name, event logo, event theme, event slogan, event song, event main color, and event mascot. The service dimension includes bus connection service, volunteer service, material supply, and parcel access, mobile toilet configuration, souvenirs, and clothing quality. Which can be used as a theoretical reference, and start from these aspects when building the event brand.

\section{CONCLUSION}

The main conclusions drawn from this study are:

Empirical analysis of related concepts. Through combing the relevant theories and the characteristics of marathon events, this study developed a scale from five elements and verified it by AMOS software. The results have shown that the brand of marathon events includes five elements: symbol element, culture element, service element, influence element and marketing element.

The reliability and validity of the scale are proved to be good by exploratory factor and confirmatory factor tests. It can be used as a tool for brand building of marathon events, and can provide competitors' attitudes and specific ways to start brand building for the event organizing committee $(\mathrm{x} 2 / \mathrm{DF}=3.668, \mathrm{RMSEA}=0.082$, $\mathrm{IFI}=0.791, \mathrm{CFI}=0.790, \mathrm{PGFI}=0.648, \mathrm{PNFI}=0.694$, The
Cronbach $\alpha$ of the total questionnaire was 0.954 , and the Cronbach $\alpha$ of the five dimensions ranged from 0.839 to 0.944).

Scale dimensions and item composition. The marathon brand element scale consists of 5 dimensions and 42 items, which are marathon brand symbol (7), marathon brand culture (6), marathon brand service (8), marathon brand influence (3) and brand marketing of marathon events (18).

\section{AUTHORS' CONTRIBUTIONS}

Meng-meng Huang collected data, analyzed data and drafted the article. Yao-Chuan Chang checked the structure and views of the article. Chuan-ming Cai made substantial contributions to the conception and design of the article.

\section{CORRESPONDING AUTHOR}

Chuanming Cai, School of Physical Education, Jimei University, Xiamen, 361000, China.

E-mail: 2920901465@qq.com

\section{ACKNOWLEDGMENTS}

The authors declare that they have no conflict of interest.The data used in this study may be requested from the corresponding author via email.The data used in this study may be requested from the corresponding author via email.

\section{REFERENCES}

[1] Wanli Wang. Research on brand construction of women's marathon "sweet run" in China[D]. Harbin Institute of physical education, 2021.

[2] Xiran Zhang. Research on brand positioning of gold standard marathon in China[D]. Capital Institute of physical education, 2020.

[3] DJ Olberding, J Jisha .The Flying Pig\&apos,:Building Brand Equity in a Major Urban Marathon [J] .Sport Marketing Quarterly, 2005:191-196. 
[4] Yiheng Chen. Research on brand building of sports events [D]. Xiamen University, 2009.

[5] Hao Zu. Shaping of brand sports events in Henan Province [D]. Henan University, 2015.

[6] Jing Hu. Research on brand building and promotion of Xi\&apos;an City Wall International Marathon [D]. North China University, 2016.

[7] Yiwen Hu, Baoling Chen, Xiangrong Ma. Brand building of campus Marathon: a case study of South China Normal University [J]. Contemporary sports science and technology, 2019.

[8] Peihui Mo Research on brand competition construction of Guilin International Marathon [D]. Guangxi Normal University, 2018.

[9] Wei Mao. Research on brand building of mass sports events in Shanghai [D]. Shanghai Institute of physical education, 2020.

[10] Zhuping Chen. Brand management [M] Beijing: China Development Press, 2005.

[11] Un Ni, Li Cai. Research on brand cultivation of ice and snow sports events from the perspective of brand cognition [J]. Sports culture guide, 2019: 99104.

[12] Jiahui Zou. Research on the international influence of Beijing brand events [D], 2013.

[13] Kevin Lane Keller. Strategic brand management [M]. Beijing: China Renmin University Press, 2003.

[14] Aaker D.A. Building Strong Brands[M].NY: Free Press, 1996.

[15] Mingyang Yu, Fangping Yang. Brand course (Second Edition) [M]. Shanghai: Fudan University Press, 2009:5-7.

[16] Xiuying Wang. Brand science [M]. Beijing: Capital University of economics and business press, 2007:108-109.

[17] Aaker,D.A.Measuring brand equity across products and markets[J].California Management Review, 1996:102-120.

[18] Keller Kevin Lane. Conceptualizing Measuring and Managing Customer-Based Brand Equity, Journal of Marketing[J], 1993 : 1-29.

[19] Chen Li. Research on brand building of Chinese martial arts competitions [D]. Central China Normal University, 2016.

[20] Jun Ni, Li Cai. Research on brand cultivation of ice and snow sports events from the perspective of brand cognition [J]. Sports culture guide, 2019: 99104.
[21] Jiahui Zou. Research on the international influence of Beijing brand events [D]. Capital Institute of physical education, 2013.

[22] Hongnian Chai. Theoretical research on brand building of sports events [M]. Beijing: People\&apos;s Sports Publishing House,2010,12.

[23] Yingai Qin. Research on the supply side reform of Marathon brands [D]. Wenzhou University, 2019.

[24] Minglong Wu. Questionnaire statistical analysis practice -- SPSS operation and application [M]. Chongqing: Chongqing University Press,2010:485.

[25] Minglong Wu Structural equation modeling: operation and application of Amos (2nd Edition) [M]. Chongqing: Chongqing University Press, 2010,10:246.

[26] Minglong Wu. Questionnaire statistical analysis practice -- SPSS operation and application [M]. Chongqing: Chongqing University Press,2010:48. 